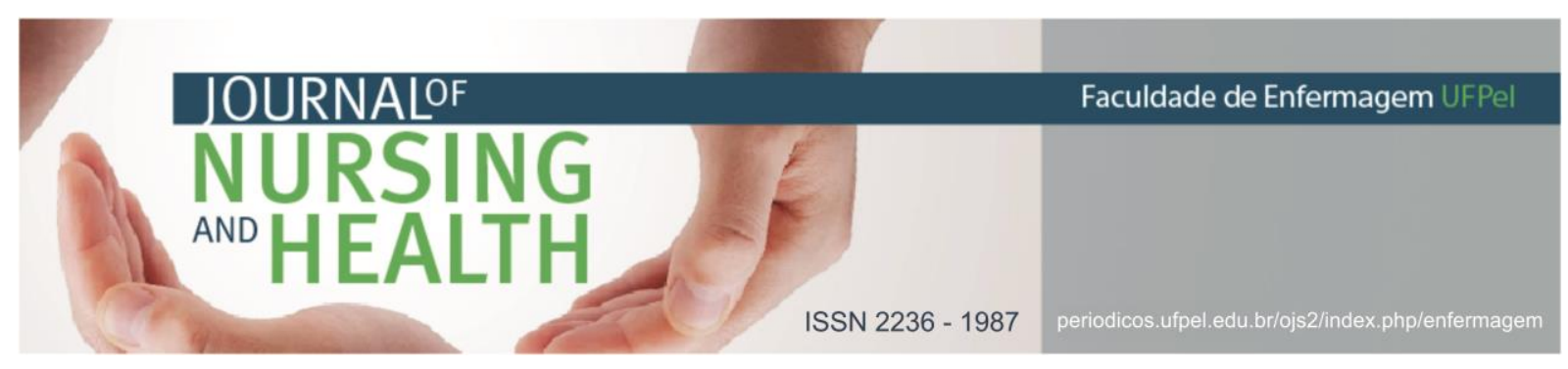

ARTIGO ORIGINAL

\title{
Inserção do lúdico como facilitador da hospitalização na infância: percepção dos pais
}

\author{
Insertion of play as facilitator of hospitalization in childhood: parental perception
Inserción lúdica como facilitador de la hospitalización en la infancia: la percepción de los padres

Rockembach, Juliana ${ }^{1}$; Espinosa, Thuane²; Cecagno, Diana ${ }^{3}$; Thumé, Elaine ${ }^{4}$; Soares, Deisi Cardoso ${ }^{5}$

\section{RESUMO}

Objetivo: conhecer a percepção dos pais quanto a inserção de atividades lúdicas durante a internação hospitalar da criança. Métodos: estudo qualitativo, descritivo e exploratório, realizado de outubro a dezembro de 2012 em um hospital no Brasil. Foram entrevistados seis pais de crianças internadas. A entrevista ocorreu em duas etapas: inicialmente, as crianças foram abordadas de forma lúdica durante os cuidados de enfermagem. Após foram realizadas entrevistas semiestruturadas com os pais. O estudo foi aprovado pelo Comitê de Ética e Pesquisa sob o número 083/2012. Resultados: da análise surgiram dois eixos temáticos: as dificuldades encontradas pelas crianças durante o período de internação hospitalar, e, os benefícios da inserção de atividades lúdicas durante a hospitalização. Considerações finais: com a utilização de atividades lúdicas, conclui-se que essas são capazes de tornar o ambiente hospitalar menos ameaçador, possibilitando resgatar sorrisos e alegria de ser criança.

Descritores: Jogos e brinquedos; Pediatria; Enfermagem pediátrica; Hospitalização.

\begin{abstract}
Objective: to know the perception of the parents regarding the insertion of play activities during the hospitalization of the child. Methods: qualitative, descriptive and exploratory study, carried out from October to December 2012 in a hospital in Brazil. Parents of six hospitalized children were interviewed. The interview was made in two stages: first, the children were raised in a playful, during nursing care. After, semi-structured interviews with the parents were conducted. The study was approved by the Research Ethics Committee with number 083/2012. Results: two theme from the analysis emerged: the difficulties faced by children during the hospitalization, and the benefits of inclusion of recreational activities during hospitalization. Final considerations: with the use of recreational activities, we can conclude that they are able to make the hospital environment least threatening, enabling rescue smiles and the joy of being a child.
\end{abstract}

Descriptors: Play and playthings; Pediatrics; Pediatric nursing; Hospitalization.

\footnotetext{
1 Enfermeira. Mestranda do programa de Pós-Graduação em Enfermagem, UFPel. Enfermeira da Prefeitura Municipal de Santa Cruz do Sul. Santa Cruz do Sul, RS. Brasil. E-mail: ju.rockembach@hotmail.com

2 Enfermeira. Residente no programa de Residência Integrada Multiprofissional Hospitalar com Ênfase na Atenção à Saúde Cárdio-Metabólica do Adulto no Hospital Universitário da Universidade Federal de Rio Grande. Rio Grande, RS. Brasil. E-mail: espinosa.thuane@hotmail.com

${ }^{3}$ Enfermeira. Doutora em enfermagem. Professora Adjunta da Faculdade de Enfermagem, UFPel. Pelotas, RS. Brasil. E-mail: cecagnod@yahoo.com.br

${ }^{4}$ Enfermeira. Doutora em epidemiologia. Professora Adjunta da Faculdade de Enfermagem, UFPel. Pelotas, RS. Brasil. E-mail: elainethume@gmail.com

${ }^{5}$ Enfermeira. Doutora em Ciências. Professora Adjunta da Faculdade de Enfermagem, UFPel. Pelotas, RS. Brasil. E-mail: soaresdeisi@gmail.com
} 


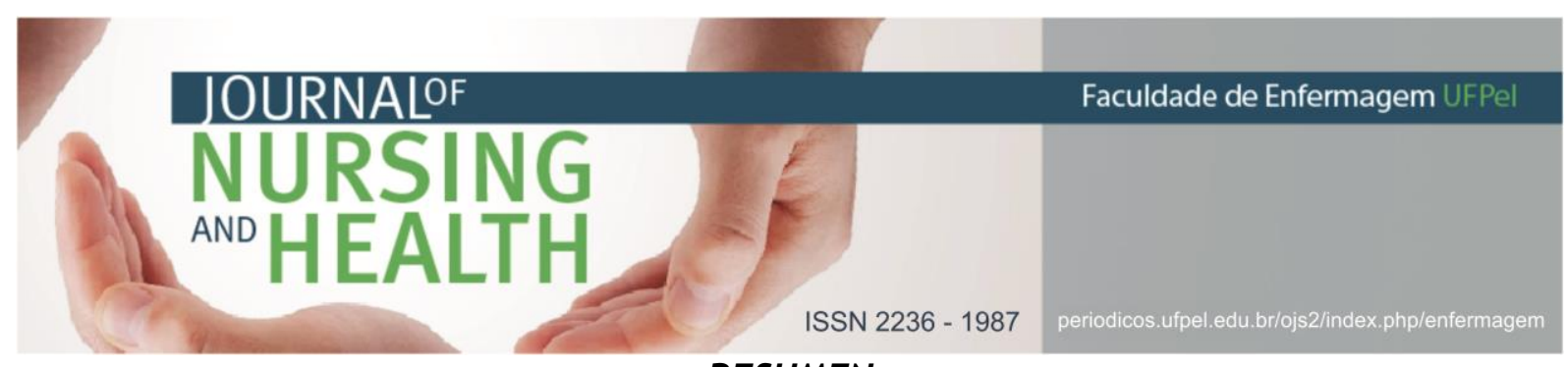

RESUMEN

Objetivo: conocer la percepción de los padres cuanto la inclusión de actividades lúdicas durante la internación hospitalaria del niño. Métodos: estudio cualitativo, descriptivo y exploratorio, llevado a cabo de octubre a diciembre de 2012 en un hospital de Brasil. Fueron entrevistados seis padres de niños internados. La entrevista ocurrió en dos etapas: inicialmente, los niños fueron abordados de forma lúdica durante los cuidados de enfermería. Después, fueron realizadas entrevistas semiestructuradas con los padres. El estudio fue aprobado por el Comité de Ética y Pesquisa baja el número 083/2012. Resultados: dos temas principales: las dificultades encontradas por los niños durante la internación hospitalaria, los beneficios de inserción de actividades lúdicas durante la hospitalización. Consideraciones finales: con actividades lúdicas, se concluye que estos son capaces de tornar el ambiente hospitalario menos amedrentador, posibilitando rescatar sonrisas y alegría de ser niño.

Descriptores: Juego e implementos de juego; Pediatría; Enfermería pediátrica; Hospitalización.

\section{INTRODUÇÃO}

A crianca, enquanto ser humano no início de seu desenvolvimento, necessita de cuidados que visam garantir seus direitos fundamentais, a fim de lhes possibilitar o desenvolvimento físico, mental, moral, espiritual e social, em condições de liberdade e dignidade. 0 Estatuto da Criança e do Adolescente (ECA) define criança como a pessoa de até doze anos de idade incompletos e adolescentes entre doze e dezoito anos de idade. Baseado nos princípios do Sistema Único de Saúde (SUS), a promoção, prevenção e assistência pressupõem o compromisso de prover qualidade de vida para a criança crescer e desenvolver o seu potencial físico, psíquico e social, mesmo diante de um momento de enfermidade. ${ }^{1}$

Almejando o desenvolvimento infantil saudável e focando o conceito que visa à integralidade do ser humano, faz-se necessário compreender que a atenção hospitalar à criança deve ser diferenciada, levando-se em conta todas as características envolvidas no processo de ser criança, entre elas o ato de brincar. $^{2}$

Quando surge a necessidade de uma internação hospitalar na infância, isso pode configurar-se em uma experiência traumática, pois afasta a criança do seu cotidiano, do ambiente familiar e promove um confronto com procedimentos dolorosos e limitações. Diferentes sentimentos e comportamentos podem aflorar nesse período, como sensação de passividade, nervosismo, preocupação, pânico, choro, angústias e medos. ${ }^{2}$ Este fato justifica a necessidade de estratégias que minimizem os sentimentos negativos advindos da hospitalização.

O brincar é uma atividade inata e espontânea da criança, brincando interage ludicamente com o mundo real, através do "faz-de-conta". ${ }^{3} 0$ lúdico está intrínseco na criança, uma vez que é a forma pela qual explora o desconhecido, adquire conhecimentos e expressa seus desejos e anseios, é a sua maneira de interagir com o mundo e manifestar sua personalidade. 


\section{JOURNALOF \\ NURSING \\ ANO HEALTH}

ISSN 2236 - 1987

universitário, em uma cidade do sul do Rio Grande do Sul, Brasil.

A unidade pediátrica possui cinco enfermarias, sendo uma delas de isolamento, uma de cuidados semiintensivos, uma para recém-nascidos, outra para distúrbios respiratórios e a última que abrange desde os lactentes até as crianças maiores. Os pacientes que internam na unidade do estudo são recém-nascidos a 26 termo e prematuros, lactentes, pré-escolares, escolares e pré-adolescentes de até onze anos. A equipe de enfermagem no turno da manhã e tarde é composta por um enfermeiro e seis técnicos de enfermagem. No turno da noite, há três enfermeiros e quinze técnicos, divididos em três equipes. Além disso, conta com acadêmicos e residentes de enfermagem, medicina, nutrição, psicologia e odontologia

Previamente à coleta de dados, o projeto foi encaminhado ao Comitê de Ética e Pesquisa da Faculdade de Enfermagem da Universidade Federal de Pelotas, obtendo aprovação com o protocolo $\quad n^{\circ} 083 / 2012$. Após aprovação, foi realizado o convite aos participantes que concordaram e assinaram o Termo de Consentimento Livre e Esclarecido em duas vias, ficando uma com o pesquisador e outra com os participantes. Os participantes da pesquisa foram seis pais de crianças com faixa etária de cinco a dez anos, internadas na Pediatria. Essa faixa etária foi escolhida pelos pesquisadores por possibilitar melhor interação das crianças com 0 pesquisador.

Os critérios de inclusão dos pais e crianças foram: criança consciente, falando, situada no tempo e espaço, e 


\section{JOURNALOF \\ NURSING \\ ANO HEALTH}

ISSN 2236 - 198

oferecer riscos à saúde das crianças, mantendo-se medidas de precaução e higiene.

Com a informação prévia da alta hospitalar da criança (fornecida pela equipe de enfermagem), foi realizada uma entrevista com os pais das crianças que participaram das atividades lúdicas. Essa seguiu um roteiro previamente estruturado, sendo aplicada na unidade em local previamente reservado, com uma duração em torno de 30 minutos. As questões do roteiro foram: 1- Explique como o(a) Senhor(a) acha que ele(a) vivencia a internação hospitalar. 2Qual a sua opinião em relação à utilização de brinquedos no âmbito hospitalar? 3- O(a) Senhor(a) acredita que a utilização de brinquedos durante a internação auxilia no tratamento e recuperação de seu filho? Por quê? 4- A equipe de enfermagem utiliza algum instrumento lúdico ao prestar assistência ao seu filho? Se sim. Quais? Como tem sido essa experiência para você e seu filho? Todas as falas foram gravadas em aúdio MP3 e posteriormente transcritas.

$\mathrm{Na}$ intenção de preservar a identidade dos participantes, foi garantido o anonimato, no qual todos os participantes foram identificados por nomes fictícios correspondentes a personagens infantis, escolhidos por eles após apresentação de uma lista de diferentes duplas de personagens. Neste estudo, foram mantidos os preceitos éticos da Resolução vigente $n^{0} 196 / 96^{5}$ e posteriormente adaptado a nova Resolução n ${ }^{\circ} 466 / 12$ do Conselho Nacional de Saúde referente à pesquisa com seres humanos. ${ }^{6}$ 
Após as entrevistas, os dados foram analisados seguindo a análise temática proposta por Minayo. ${ }^{7}$ Seguindo as seguintes etapas: ordenação de dados, classificação e embasamento teórico, análise final e interpretação dos dados obtidos. Dos dados, emergiu dois eixos temáticos: Dificuldades encontradas na hospitalização e os benefícios do lúdico na hospitalização da criança.

\section{RESULTADOS E DISCUSSÕES}

Dos seis pais que participaram desta pesquisa, cinco eram mães e um pai, com faixa etária entre 24 e 40 anos, a maioria com escolaridade de Ensino médio incompleto, solteiro, com profissões distintas, com número de filhos entre 01 e 04 . Em relação aos filhos internados, foram cinco meninos e uma menina, com idades entre $05 \mathrm{e}$ 10 anos, os diagnósticos variaram entre respiratórios, um por leucemia, um por colite ulcerativa e um por hemofilia.

\section{As dificuldades encontradas na hospitalização}

Nas entrevistas, os pais relataram os sentimentos que emergiram durante a hospitalização, a demonstração de medo, saudade de casa e agressividade demonstradas pela criança com relação ao ambiente hospitalar, foram situações que interferiram negativamente durante o período de internação. As atividades lúdicas, no entender dos pais, foram benéficas na adaptação na Unidade Pediátrica, uma vez que modificaram comportamentos negativos e trouxeram benefícios durante a internação da criança.
Os participantes do estudo apontaram que 0 processo de hospitalização interferiu no comportamento de seus filhos, que apresentaram angústia, medo, aflição e algumas regressões comportamentais.

Era bem difícil vir para o hospital [...] ele não aceitava, ficava com medo de tudo, nem queria tomar banho (Minnie, mãe de Mickey).

É difícil pra ele porque ele tem medo da medicação e sente falta da família (Mônica, mãe de Cebolinha).

Ele ficou apavorado [...], se comoveu de ver os bebês, com a mesma coisa que ele [...]. Ele nunca tinha visto pessoas vestidas de branco (Robin, pai de Batman).

Ao verbalizar que o filho não aceita a hospitalização, demostra medo da medicação e fica apavorado, nota-se isso como parte do processo inicial de hospitalização, devendo ser contornado ao oportunizar um ambiente propício ao ser criança.

Com o afastamento de seu cotidiano e sua nova condição de paciente, a criança passa a ter sua própria percepção sobre a nova realidade, teme o desconhecido e as situações desagradáveis. ${ }^{8}$ Surge a necessidade de adaptar-se a novas rotinas e horários, confiar em pessoas até então desconhecidas, e permanecer em um quarto com privação de realizar atividades que caracterizam sua vida de criança. De acordo com a faixa etária dessa criança, a hospitalização pode afetar o 
seu desenvolvimento infantil saudável, interferindo diretamente na sua qualidade de vida, mesmo após a alta hospitalar.

Tendo em mente a assistência que visa a integralidade do ser humano, faz-se necessário que a criança tenha em sua disposição instrumentos de seu domínio, que sejam do seu conhecimento e convívio, entre os quais estão os brinquedos, atividades do cotidiano delas. Neste sentido, é indispensável refletir que o lúdico está presente na infância como parte fundamental para definir o que é "ser criança", tendo a capacidade de esclarecer, auxiliar, aliviar temores, ansiedade, bem como intermediar 0 que a criança pensa e sente. ${ }^{8}$

\section{Benefícios do lúdico na hospitalização da criança}

Em relação aos benefícios, o lúdico foi relatado pelos pais como forma de criar uma nova realidade, em que as crianças repetiam através de brincadeiras momentos dolorosos advindos de procedimentos e da própria internação. Durante a brincadeira, ao assumirem o papel do médico e enfermeiro, davam uma injeção em sua boneca, repetindo as palavras: "não vai doer". Assim, com a repetição da situação há um fortalecimento em termos de idealização, criando através de seu mundo imaginário uma nova situação. Nas falas a seguir, pode-se perceber que após as atividades lúdicas, os pais relataram que as crianças tiveram melhor adaptação na unidade pediátrica:
Ele reagiu bem [...], ele achou bem animado $o$ hospital, desenhou a piscina de bolinhas, a salinha de recreação (Minnie, mãe de Mickey).

Ela tem encarado de uma boa forma, está achando bom, não está depressiva [...], ela se identificou bem com o ambiente, principalmente, a salinha de brincar (Rapunzel, mãe de Cinderela).

Ele parece que está em casa [...], ele gostou desse hospital. Ele gosta e diz que é o melhor por causa das brincadeiras (Sininho, mãe de Peter Pan).

Ele tem ficado mais animado e te diz que está bem que está se sentindo em casa [...], as brincadeiras distraem bastante [...], meu filho agora já sorri. Ele estava triste (Robin, pai de Batman).

É a partir dos três anos de idade que as situações assumem caráter simbólico na vida da criança, tendo a capacidade de representar situações vivenciadas por ela e servindo como forma de criar uma realidade individual. ${ }^{9}$ Neste ínterim, o lúdico torna-se um instrumento capaz de modificar a realidade negativa em algo positivo, como uma forma de oportunizar uma melhor elaboração dos conflitos por ela vivenciados. ${ }^{10}$

O lúdico consegue modificar o imaginário infantil uma vez que possibilita modificar o olhar sobre o adoecimento e sobre as suas consequências negativas. Através dos desenhos, jogos e conversas, repetiam 


\section{ISSN 2236 - 1987}

no "faz-de-conta" os acontecimentos que vinham enfrentando, sendo um recurso no qual a criança tem a possibilidade de se expressar e comunicar-se com o "mundo adulto". No âmbito hospitalar, a criança consegue expor seus medos, angústias e dúvidas, bem como assimilar as intervenções e as dificuldades com que se depara. ${ }^{11}$

Pode-se perceber através do que os pais expressaram que, com a utilização do lúdico, seus filhos tiraram de foco a doença e a hospitalização, direcionando para as brincadeiras:

Ele usando os brinquedos se distrai e pensa em outras coisas. Deu pra aliviar a tensão de estar dentro de um hospital [...], ele não fica só pensando na medicação. Vai na salinha de brinquedos e brinca (Mônica, mãe de Cebolinha).

Mesmo com a dor, ela está se distraindo e para ela está sendo muito bom [...], as brincadeiras distraem e ela esquece da dor (Rapunzel, mãe de Cinderela).

Ele só ficava na cama $e$ choramingava, querendo ir embora. Agora que ele começou a brincar, ele já não fica mais falando, ele só fica pedindo pra ir ali brincar (Fiona, mãe de Shrek).

O lúdico exerce contribuição para minimizar os traumas da doença e da hospitalização, é uma alternativa para a resolução dos conflitos encontrados. Logo pode-se afirmar que a criança quando brinca consegue expressar sentimentos e receios, sentindo-se descontraída e feliz, tornando sua permanência hospitalar mais fácil. ${ }^{11}$

Corroborando, o lúdico é algo prazeroso à criança, torna o ambiente hospitalar menos aversivo, favorece o desenvolvimento infantil, traz alegria e também resgata sua própria condição de "ser criança". ${ }^{12}$ A ludicidade tornase um contraponto às experiências dolorosas da hospitalização, que nesse sentido vai além da dor física provocada pela doença ou pelos procedimentos, passando a ter um conceito de sofrimento psíquico e existencial.

Além dos benefícios para a adaptação da criança na unidade de internação Pediátrica, o lúdico propicia um momento prazeroso com função terapêutica. 0 ato de brincar é visto como uma terapia na medida em que pode ser percebido como um instrumento capaz de tranquilizar a criança, favorecer a compreensão da situação experenciada por ela e permitir que o profissional tenha acesso, de forma mais plena, ao universo infantil. ${ }^{11}$

Neste ínterim, o lúdico é uma ação sobre 0 próprio corpo, promovendo um equilíbrio físico e mental, ajudando na regulação de tensões e estresse, sendo capaz de fazer bem à saúde.

De acordo com as falas a seguir, podemos perceber que para os pais a realização de atividades lúdicas teve ação direta no prognóstico positivo de seus filhos:

Ele fica com mais vontade, tem mais força de se curar, de melhorar... se sente um pouco melhor, porque antes ele estava 
lá tristinho, só tinha febre, só ficava deitado. Depois que ele começou [...] ir ali brincar, começou a andar mais, melhorou (Fiona, mãe de Shrek).

Ele estava 'pra baixo' $e$ no momento que ele viu pessoas alegres conversando e cuidando dele [...] fazendo atividades, brincando, mexendo com ele. Fazendo com que ele risse, sempre levantando o astral dele [...], eu me surpreendi, se a recuperação é de 20 dias, em menos ele consegue se recuperar, os brinquedos 'tão' ajudando muito ele (Robin, pai de Batman).

A utilização de instrumentos hospitalares fictícios e bonecas, oportunizou para as crianças conhecer, experimentar e repetir o procedimento brincando, adquirindo assim, conhecimentos em relação ao cuidado a que estavam sendo submetidos e passando a percebê-los de forma menos ameaçadora.

Os benefícios da utilização do brinquedo durante os procedimentos dolorosos estão expressos nas falas de Robin e Fiona:

Brincando ele fica relaxado, deixa realizar os procedimentos numa boa (Robin, pai de Batman).

[...] mais fácil pra vocês examinarem e pra tratar ele também (Fiona, mãe de Shrek).

Corroborando que a relevância do brinquedo terapêutico durante os procedimentos, é uma possibilidade de
ISSN 2236 - 198

conexão entre a racionalidade científica das práticas de saúde e a subjetividade contida dentro de cada criança, este permite que 0 tratamento extrapole os procedimentos técnicos. ${ }^{13}$ Os materiais que comumente causam temor, tornam-se brinquedos no imaginário infantil, fazendo com que a criança consiga enfrentar as ações doloridas e invasivas com uma ideia de que aquilo também é uma brincadeira.

Como pode ser percebido, as brincadeiras tornaram-se fundamentais, pois garantiram alegria e favoreceram de forma positiva o tratamento. O lúdico é capaz de diminuir expressivamente a angústia e dor que são caracterizados como prejuízos oriundos da hospitalização.

Sua relevância, também é percebida por enfermeiros pediatras, cujos benefícios percebidos envolvem a criança, a família e os profissionais. Para estes, o brincar torna o ambiente mais familiar, ajuda na aproximação e interação com a criança, tornando-se um instrumento terapêutico. ${ }^{14}$

Deste modo, neste estudo, o brincar passou a ser visto como um espaço terapêutico capaz de promover a continuidade do desenvolvimento infantil e possibilitou que a criança conhecesse e se adaptasse ao novo ambiente, contribuindo de forma positiva no tratamento e prognóstico, reduzindo possíveis traumas futuros. Como limitações do estudo, identificou-se resistência dos membros da equipe na utilização de atividades lúdicas. Entretanto, acredita-se que este estudo traz novos olhares sobre as necessidades das crianças durante a internação, para que acadêmicos de 
enfermagem e enfermeiros pensem em uma enfermagem mais humana $e$ melhor.

\section{CONSIDERAÇÕES FINAIS}

$\mathrm{Na}$ proposta desenvolvida, o lúdico adquiriu aplicação terapêutica, ajudando a criança na compreensão e melhor aceitação de procedimentos invasivos. A brincadeira teve o intuito de apresentar o procedimento, explicar sua importância, necessidade, dar oportunidade para que a criança pergunte $e$ interage de maneira colaborativa durante o mesmo.

Sendo a hospitalização, um episódio cercado por inúmeras dificuldades, o lúdico tornou-se uma ação fundamental, neste estudo, uma vez que foi o modo pelo qual a criança interagiu e se expressou. Torna-se necessária uma modificação na maneira de trabalhar o cuidado à criança, tendo em mente a singularidade e a forma na qual a criança vivencia o adoecimento e a hospitalização. Assim, é ímpar buscar novas formas de cuidar, ultrapassando as barreiras do modelo técnicocientífico, acrescentando-lhe amor, afetividade e empatia na experiência vivenciada pela criança.

Segundo a percepção dos pais, pode-se inferir que a estratégia utilizada amenizou o processo de internação da criança na unidade pediátrica em estudo, uma vez que foram inseridos momentos de diversão, resgatando as características infantis. As crianças se mostraram receptivas à atividade, participando ativamente da proposta e, diante disso, o ambiente hospitalar se tornou menos hostil e ameaçador, facilitando a adesão ao tratamento. Diante dos resultados deste estudo, indica-se a utilização do lúdico, no cotidiano da enfermagem pediátrica, como uma estratégia de baixo custo e com retorno imediato, tanto para as crianças quanto para os familiares.

\section{REFERÊNCIAS}

1. Brasil. Lei $8.069 / 90$ atualizado com a Lei $n^{\circ} 12.010$ de 2009. Dispõe sobre o estatuto da criança e do adolescente e dá outras providências. Diário Oficial da União. 3 de agosto de 2009; Sessão $1: 1$.

2. Gesteira ECR, Franco ECD, Braga PP, Criscuolo MBR, Oliveira JS. Contos infantojuvenis: uma prática lúdica de humanização para crianças hospitalizadas. Rev enferm UFSM. 2014;4(3):575-83.

3. Ferreira NAS, Esmeraldo JD, Blake MT, Antão JYFL, Raimundo RD, Abreu LC. Representação social do lúdico no hospital: o olhar da criança. J hum growth dev. 2014;24(2):188-94.4. Jansen MF, Santos RM, Favero L. Benefícios da utilização do brinquedo durante o cuidado de enfermagem prestado à criança hospitalizada. Rev gauch enferm. 2010;31(2):247-53.

5. Ministério da Saúde (BR). Conselho Nacional de Saúde. Resolução 196, de 10 de outubro de 1996: diretrizes e normas regulamentadoras de pesquisa envolvendo seres humanos. Brasília; 1996.

6. Ministério da Saúde (BR). Conselho Nacional de Saúde. Resolução 466, de 12 de dezembro de 2012: diretrizes e normas regulamentadoras de pesquisa 
envolvendo seres humanos. Brasília; 2012.

7. Minayo MC. 0 desafio do conhecimento: pesquisa qualitativa em saúde. $14^{\mathrm{a}}$ ed. São Paulo: Hucitec; 2014.

8. Oliveira DKMA, Oliveira FCM. Benefícios da brinquedoteca à criança hospitalizada: uma revisão de literatura. Rev bras cienc saude. 2013;11(35):37-44.9. Leite MAVS, Neves NVG, Barreto MLM, Castro RS, Jesus CT, Silva R, et al. Brinquedoteca hospitalar: o lúdico como instrumento de mediação na recuperação de crianças enfermas. Revista ELO Diálogos em Extensão. 2013;2(1):3350.

10. Depianti JRB, Silva LF, Carvalho AS, Monteiro ACMN. Nursing perceptions of the benefits of ludicity on care practices for children with cancer: a descriptive study. Online braz j nurs. 2014,(13)2:158-65.

11. Jonas MF, Costa MADJ, Souza PTL, Pinto RNM, Morais GSN, Duarte MCS. O lúdico como estratégia de comunicação para a promoção do cuidado humanizado com a criança hospitalizada. Rev bras cienc saude. 2013;17(4):393-400.

12. Hostert PCCP, Enumo SRF, Loss ABM. Brincar e problemas de comportamento de crianças com câncer de classes hospitalares. Psicol teor prat. 2014;16(1):127-40.

13. Oliveira SR, Almeida NA. As expressões lúdicas como terapêutica na hospitalização: revisão integrativa. Revista eletrônica gestão \& saúde. 2016; 07(1):356-68.
14. Oliveira CS, Maia EBS, Borba RIH, Ribeiro CA. Brinquedo terapêutico na assistência à criança: percepção dos enfermeiros das unidades pediátricas de um hospital universitário. Rev soc bras enferm ped. 2015;15(1):21-30.

Data de submissão: 18/02/2016

Data de aceite: 24/08/2017

Data de publicação: 30/08/2017 